\title{
Infrastructural Development and Vulnerabilities: A Sociological Study of Two Selected Flyovers in Dhaka City, Bangladesh
}

\author{
Shamsul Arefin ${ }^{*}$, Tamanna Rashid1, Didarul Habib ${ }^{2}$ \\ ${ }^{1}$ Lecturer, Department of Sociology, Bangabandhu Sheikh Mujibur Rahman Science and Technology University, Gopalganj, Dhaka, \\ Bangladesh \\ ${ }^{2}$ Freelance Researcher, University of Dhaka, Dhaka, Bangladesh \\ Email: *shams.rehan@bsmrstu.edu.bd, tamannarashid14@gmail.com, urs.sufol@gmail.com
}

How to cite this paper: Arefin, S., Rashid, T. and Habib, D. (2019) Infrastructural Development and Vulnerabilities: A Sociological Study of Two Selected Flyovers in Dhaka City, Bangladesh. Open Journal of Social Sciences, 7, 18-29.

https://doi.org/10.4236/jss.2019.77003

Received: May 16, 2019

Accepted: July 8, 2019

Published: July 11, 2019

Copyright $\odot 2019$ by author(s) and Scientific Research Publishing Inc. This work is licensed under the Creative Commons Attribution International License (CC BY 4.0).

http://creativecommons.org/licenses/by/4.0/

\begin{abstract}
Does infrastructural development cause underdevelopment of the third world peripheral states like Bangladesh? Can flyover project overcome traffic congestion? Does it create vulnerabilities for the common people? This paper is an attempt to answer all the above questions. Depending on the qualitative research design, this study was conducted on the two selected flyover projects in Dhaka, Bangladesh named Mayor Hanif Flyover and Khilgaon Flyover. Theoretical arguments of development and underdevelopment on modernization and dependency school were incorporated for critically examining this research. Hence, the researcher followed conflict approaches given by $\mathrm{Da}-$ hrendorf (1959), later used Coser (1956) and Guangshe Jia, et al.'s (2011) arguments to understand how mega projects like flyover operate through different channels in third world countries. The study then reveals that although these mega projects benefited communication system, it literally failed to fulfill public core demands and interests by making people marginalized and vulnerable. Besides, this study explored that mega projects like flyover are an outcome of bureaucratic decision in which social and environmental impact assessment was ignored.
\end{abstract}

\section{Keywords}

Infrastructural Development, Underdevelopment, Flyovers, Vulnerability

\section{Introduction}

Infrastructure matters to growth are relatively well recognized and widely understood among practitioners and policymakers. There is a technical evidence 
that better quantity and quality of infrastructure can directly raise the productivity of human and physical capital and thus it promotes growth. It is stated that infrastructural development improves education and markets for farmer's outputs and others by cutting costs, facilitates private investment, and improves jobs and income levels for many others. Energy and transport are essential elements of the modern production along with the distribution processes as well as the efficiency and the relative cost of these inputs are often a key determinant of competitiveness in the global economy. The World Economic Forum regularly updates countries position on competitiveness based on 12 pillars. Infrastructure (transport and energy infrastructure) is one of the key pillars [1]. In the World Economic Forum's Global Competitiveness Report 2009-10, the country's infrastructure competitiveness was ranked 126th out of 133 countries, the lowest ranking among its South Asian neighbors, India (49th), Sri Lanka (79th) and Pakistan (101st) [1] [2]. Transport facilities are severely lacking in Bangladesh, causing traffic bottlenecks that drive up the cost of business and goods. The country's capital, Dhaka, is notoriously crowded and port congestion is a major problem. According to the Demographia World Urban Areas, Dhaka is reported to be one of the most densely populated megacities of the world with a density of 115,000 people per square mile and for the informal dwellings, the density is reported as 2.7 million per square mile [3]. The prevailing urban condition in Dhaka with such a density continuously fails to adequately meet the social or economic needs of marginalized community. With escalating land values and rising everyday living expenses, low-income people who cannot afford land in urban Dhaka; look for opportunities within the urban voids for their livelihood activities. Scarcity of spaces in the city makes any urban voids a precious resource for poor urban households [2]. Since the early stage of development, the Government of Bangladesh (GOB) focused on smoothing traffic flows with the growing population densities and increasing traffic demand [2]. The Government of Bangladesh wants to invest $\$ 8$ billion over the next few years in infrastructure to improve the economy and seeks help from private sector to share the cost which the government could not bear alone [4]. Due to the colonial interventions, after the liberation war, Bangladesh experienced weaker infrastructural development as it was the main hindrance of economic growth and prosperity. But for the last two decades, the conditions improved as private sector and foreign direct investment came forward to solve the problem. The Government has already identified the following high-priority projects for the transport sector: Construction of Padma Multipurpose Bridge over the mighty river Padma, Construction of a tunnel underneath the Karnaphuli river in Chittagong, Conversion of sought nationally important highways into four lanes gradually, Continuation of investment to reform and modernize railways, Construction of the 3rd Seaport at Payra in Patuakhali, Construction of a seaport and an LNG terminal at Moheshkhali, strengthening fleet capacity while making Biman a profitable organization by improving its management and enhancing the capacity of passenger transport, Construction of Rooppur Nuclear Power Plant 
Project, Rampal Coal-fired Thermal Power Plant and Dhaka Mass Rapid Transit Development Project (Metro Rail Project). Given the importance of transport sector in improving competitiveness and growth the Government has also been allocating significant resources through the ADP. The Government allocated relatively large public resources (46\% of total ADP in FY2014) through the ADPs to the Power, Energy, and Transportation sectors. In fact the infrastructure Ministries/Divisions have repeatedly been among the top 10 recipients of ADP allocations since FY11. It is evident that Transportation and Power sectors have been receiving the highest ADP allocations in line with the priority placed on developing the infrastructure [4]. Besides, a number of measures have been undertaken to improve on multimodal and integrated urban transport system. Some of the associated infrastructures have been completed. The strategic plan by the GOB for sorting out the bottleneck problems at the intersections came out with the construction of flyovers over the bottleneck points. Accordingly, in the year 2004, GOB built the first flyover at Mohakhali intersection [2] [5]. As described in Taleb and Majumder, the $1.12 \mathrm{~km}$ 4-lane flyover was built by first Metallurgical Construction Limited, a Chinese firm, under the World Bank funded Dhaka Urban Transport Project (DUTPII) and was implemented by the Roads and Highways Department (RHD). The construction cost was about BDT 116 crore (14 million USD). The second flyover was built at Khilgaon, which was commissioned on March 22nd, 2005. The $1.9 \mathrm{~km}$ two lane flyover made completely by the local experts. Local firm Development Construction Limited (DCL) built the flyover on internal funds and the Local Government Engineering Department (LGED) implemented the project. The flyover was constructed at a cost of about BDT 81.75 crore (10 million USD) [2] [5]. In December 2014, the government undertook a $\$ 129.37$ million project to build $13 \mathrm{~km}$ long Shantinagar-Jhilmil flyover in Dhaka. The $13 \mathrm{~km}$ long Shantinagar-Jhilmil flyover will be constructed with a view to establishing a direct and uninterrupted link with the capital Dhaka. Since then, a number of large and small ad-hoc flyovers are being constructed at different congested intersections of Dhaka city [2]. Although these flyovers are helping out people in many ways, but different study reported that those are also creating immense pressure as well as vulnerabilities to the people. According to Dr. Mohammad Shakil Akhter, an Assistant Professor of URP Department of BUET, "All over the world, there is a growing consensus against flyovers. Flyovers are not only an eye-shore but also the symbol of failure to curb traffic congestions" [6].

In this backdrop, this study is an attempt to explore the relationship between infrastructural development (through flyover project) and vulnerabilities of the people. Considering Dhaka City's two major flyover projects e.g. Mayor Hanif Flyover and Khilgaon Flyover, this study will try to seek answers to the following questions: What are the changes that have taken place after the construction of flyovers? What types of vulnerabilities are being created due to flyovers in Dhaka city? In what different ways, marginal people and neighborhood embrace the flyovers? Are development and underdevelopment (vulnerabilities) 
interlinked?

\section{Literature Review}

At present, there is lacking of research endeavors that established relationships between flyovers and infrastructural development in Bangladesh. As flyovers are a recent experience, very few works have been published on different journals. Most of the existing literatures on flyovers contain spatial analysis and they lack critical analysis.

In an article, How to overcome the infrastructure deficit in Bangladesh, Bosunia said that most of our so-called flyovers do not meet the criteria of an effective, standard flyover. For instance, the Mohakhali flyover is more suited to be called an overpass. The flyover from Bijoy Sharani to the Rangs building can be considered as a connecting over bridge. There is also a flyover for left-hand drive vehicles in Dhaka, which makes no sense in a city that caters solely to right-side drive vehicles. The flyover at Kuril, however, fulfills the criteria of a proper flyover [7].

Taleb and Majumder in their study highlighted the negative impact of flyovers over the adjacent areas. They argued that the flyover construction worsens the visual impact and the benefits of the local people are extremely negligible. To them,

" $A$ few shops are fully and a few shops are partly damaged during the construction of flyover. A large number of people are affected for construction of flyover. Monthly income of businessman has decreased after construction of flyover. Job opportunity has decreased on the adjacent shops" [5].

Moreover they found some specific negative impacts of flyover construction at Mohakhali and Khilagaon such as: construction of flyover causes loss of lands, displacement of population and loss of social cohesion, a negative effect on the economic activities, loss of employment, a significant damage of infrastructure of private and public property, potential health hazards, negative impacts on environment, increasing accidents on the adjacent areas and increasing traffic congestion on the surrounding areas [5].

Akhter in his article, A Big No to Flyover and Subway in Dhaka, focuses on the city's Strategic Transport Plan (STP) and other transport related policies and suggested that from social, financial and economic point of view there is no scope for flyover in Dhaka. In section nine (Policies for Dhaka) of the policy it was stated that bus service and pedestrian would be prioritized and commuter rail would be introduced. He also gave an example from Bangkok. To his utterance,

"To eradicate traffic congestion in Bangkok Thai government implemented an ambitious plan of series of flyovers with metro (consisting of underground and elevated rail) in and around Bangkok in the early 1990s. However it did not eradicate problem instead it encouraged people to buy more cars. In boom period 1000 cars were added daily in Bangkok traffic and now congestion of $1980 \mathrm{~s}$ is 
returning to Bangkok' [8].

In Seoul and Tokyo flyovers have been dismantled or in the process of dismantling. Flyover does not decrease congestion but increase congestion. They are bad for business as well as they decrease real estate value in the locality [8].

Roushan, examined the spaces under the flyovers, and proposed some design interventions. According to her study, most spaces under them will be inaccessible, forgotten and turned into a haven for illegal activities as the flyovers emerged out of the dense framework of the city [2] [9].

Moreover, Kabir in his study explored that the use of the "flyunder" space can be seen as a result of negotiations between different actors based on existing power structure and power relations. For him,

"The space has been claimed by local leaders affiliated with the political party, who successively become the new'owner' of the space" [2].

He also said that the "flyunders" are embraced by the community in various ways, according to their diverse needs. The users of this space belong mainly to lower income groups especially women and children. As general living standard continues to rise, low income people who cannot afford expensive urban land, utilize the overlooked spaces as a way to earn their livings. Children take "flyunder" after school for their play. Sometimes during off-peak period, people go for recreational evening walks on the flyover and enjoy the city view [2].

\section{Theoretical Framework on Development and Underdevelopment}

During the early period of development efforts there was little discussion on the historical causes and the real nature of underdevelopment. Theoretical considerations at the time of "cold war" explained the situation of underdevelopment and the path for development from the viewpoint of western or socialist metropolis. Only in more recent times the viewpoint of developing countries gained momentum in development theory.

In the 1950s and early 1960s modernization theory was developed by a number of social scientists, the most prominent of them was Talcott Parsons, Lerner and W.W. Rostow. It spelt-out the implication for the geography of a global system divided into centers of modern progress and peripheries of traditional backwardness, with the center showing the periphery its future [10]. According to modernization theories, internal factors in the countries, such as illiteracy, traditional agrarian structure, the traditional attitude of the population, the low division of labor, the lack of communication and infrastructure, etc., are responsible for underdevelopment. Consequently, a change of these endogenous factors is the strategy for development. The industrialized countries are the model for economy and society, and this model will be reached sooner or later [11].

On the other hand the modernization theory was contested by the dependency theories. This model relates to the scholars like Andre Gunder Frank, Samir Amin, Immanuel Wallerstein and H. Magdoff. For dependency theorists, Euro- 
pean development was based on external destruction: brutal conquest, colonial control, and the stripping of non-Western societies and their people, resources, and surpluses [10]. The development of industrialized countries and the underdevelopment of developing countries are parts of one historical process. The economic and political interests of industrialized countries determine their development or under development. As Frank said, "The growth of the advanced industrial center in the world today meant the simultaneous underdevelopment of those countries whose economic surplus the West exploited. Poor societies should not therefore be regarded as in some way' immature; or 'underdeveloped' in their economic development, given time, their growth will occur. So long as they are subject to the dominance of the economic imperialism of the West their poverty will persist' [11]. So, underdevelopment is not backwardness but intentional downward development. As to the causes of dependence, the various theories differ, but economic factors always remain dominating.

Moreover, social scientists agreed that under the colonial rule, state didn't exist in a modern sense. According to Marx, colonial state was the sole agent for exploiting capital and class relations. Following Poluontaz, it can be argued that the British colonial power and the post-colonial states in India and Bangladesh strengthened governance structure which were dominated by the dominant economic classes. Besides, Hamza Alavi took a Marxist view in his article titled "The State in Post-Colonial Societies: Pakistan and Bangladesh". He argued that the state's prominent position in post-colonial society is rooted not only in the colonial legacy, but also in the contemporary production process [12]. This is evident in a post-colonial state, which directly appropriates almost all economic surpluses and invests it in bureaucratically designed economic activities. In Alavi's view, the military-bureaucratic oligarchy is the real elite who participate in the political game to play a semi-autonomous role beside the state for establishing a direct control over the society. So in the context of State's theory development is exercised by the State through the bureaucratic-military oligarchy to keep control and domination for the Capitalist [12].

Now, we need to understand flyover projects and how it operates through different channels. We can easily relate Dahrendorf's conflict approach which believed that the unequal distributions of authority and power within the social organization makes a society prone to conflict [13]. Another theorist, Coser explored the ideas set forth by Georg Simmel which depicts conflict as "a form of socialization" [14]. Coser's views pointed out those conflicts having positive effects by reducing the possibility of the division of the society in two classes and ensuring social continuity. He uttered that a mega project can cause a conflict and conflict can cause a mega project [14]. The latter case is usually rarely noticed. A conflict can lead to the emergence of a mega project that can have many positive functions in solving the conflict. For example China's 4 trillion Yuan investment of construction project proved to be effective to revive the economic problems. Guangshe Jia, et al. tries to develop a sociological perspective of mega 
projects on the basis of conflict approach [15]. They proposed three propositions about the mega projects-

1) Mega project is the outcome of social conflict.

2) Mega project functions as a safety valve in society.

3) Mega project has a close relationship with the level of political centralization and economic development.

First proposition assumes that as long as core values of society are not harmed conflicts can help to improve the society and reveal unreasonable social rules. The improvements are not created by the conflicts themselves. They are created by people when they notice conflicts and start to try to solve them. In the long run mega projects can reduce unemployment and simulate economy. Second proposition argues that conflicts function like the safety valve on a boiler. They ceased the hostility and dissatisfaction of people. Third assumption of this model states that the scale of the project is related to how much there is a level of centralization in the society. Where there is higher level of centralization the people are more willing to sacrifice their individual interests for collective wellbeing. Another point is, mega project does not always give the solutions for conflicts. If mega project fails, it can generate even more problems and in worst case the destruction of the whole society [15].

\section{Developing Conceptual framework from theoretical framework}

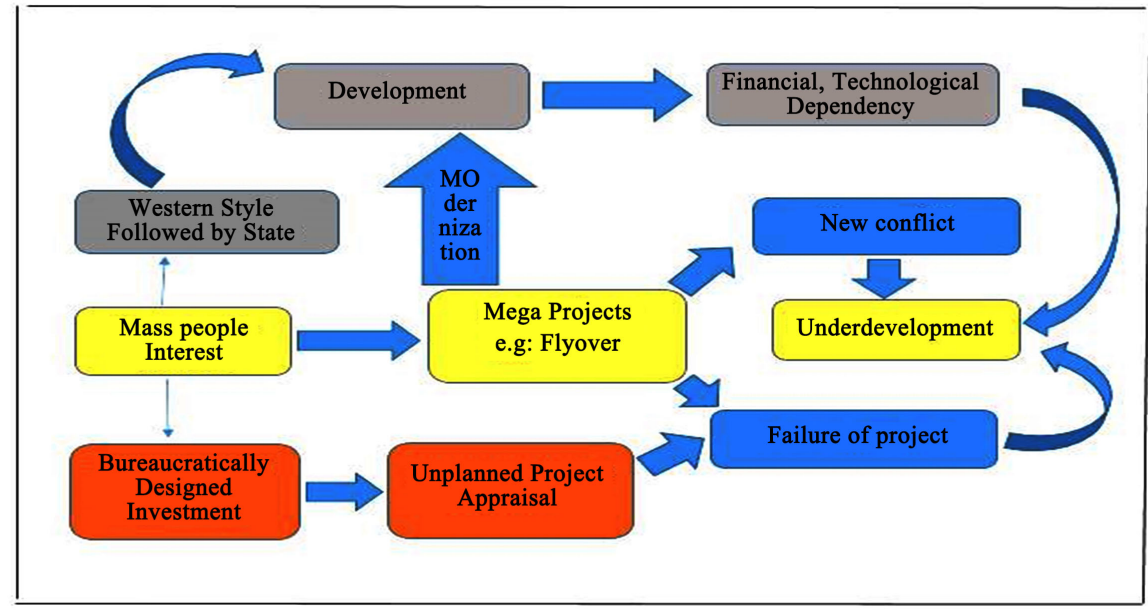

Linkage between development and underdevelopment.

\section{Methodology}

In 2016 (authors) conducted a study over a period of two months (July-August) on two local sites (Mayor Hanif Flyover and Khilgaon Flyover) in Dhaka city to explore the relationship between development and vulnerabilities. This field work incorporated qualitative methodology with the techniques of site observations, in-depth interviews and informal discussions with different categories of people. About 15 respondents were purposively selected for in-depth interviewing. Respondents were mainly local residents, local businessmen, service holder and pedestrians. Besides some informal discussions were conducted to justify the 
findings of the in-depth interviews. Moreover, various literary works on infrastructural development and flyover projects from different sources were critically examined. All the collected data and necessary documents were then critically reviewed and analyzed and concluded with necessary recommendations.

\section{Limitations}

This study lacks the quantitative methodology as we think that it can enhance the validity of this research. Time constraints and limited resources confined this study to two flyover case studies in Dhaka. Besides, this study lacks expected respondents and thus difficult to generalize. Moreover, this study can be very dynamic if global context could be added.

\section{Findings and Discussions}

An adequate and efficient transport system is a prerequisite for sustainable economic development. As Mayor Hanif and Khilgaon flyover are considered as the connecting node between central city and the northern western fringe arena, it has remarkable role in the greater Dhaka transport context. These flyovers were built to eradicate the traffic congestion of the city with the help of public and private collaboration. Although these mega projects benefited communication system, but it literally failed to fulfill public core demands and interests. Before the construction of Mayor Mohammad Hanif Flyover, it took several hours to reach Jatrabari, Shonir Akhra as well as Narayanganj from Azimpur. But now it only requires 25 - 30 minutes to connect these areas. The same scenario is observed in case of Khilgaon Flyover. It has made distance communication flexible and time saving. While talking with several respondents one of them uttered that, "Many things have improved, communication became easier from the distant places, but traffic congestion increased. Illegal activities increased. Hawkers and informal workers increased their business, but local businesses decreased. Moreover, the transport drivers are not utilizing the flyover as it cost excessive tolls. As a result, it is creating pressure under the flyover. It hindrance pedestrians movement under the flyover and caused serious damage for them." (Lipon, Age 45, Businessman, Khilgaon Fly over, Dhaka)

At the same time the peripheral zones of Dhaka city like Jatrabari, Shonir Akhra, have been developed same as central Dhaka. Prices of land, house rents of that areas, have been increased. Many new economic activities also emerged on that areas due to the flyovers. Most of the respondents from Khilgaon and Gulshan areas said that these flyover projects decreased house rents and land prices of the nearby adjacent areas, but it increased the prices of land and house rents in the peripheral areas. One of the respondents from the Mayor Hanif Fly over project said that, "before the flyover being constructed, I had plan to rebuild my house. I have contacted with a real estate development company. They had plan to rebuild my house, but finally they discarded the contract due to the construction of this flyover. Besides the prices of land in this locality also decreased 
compare to other areas like Bashundhara, Gulshan, Banani and even in those peripheral areas like Savar, Narayanganj etc.".

Another point is, mega project does not always give the solutions for conflicts. If mega project fails it can generate even more problems and in worst case the destruction of the whole society. For example Mayor Mohammad Hanif Flyover helps to flourish the peripheral areas of Dhaka city, at the same time it creates urban refugees as well as various vulnerabilities like air pollution, noise pollution, water logging etc. Many people and organizations have also been displaced forcefully. While conducting participant interviews within the two projects, we found that most of the respondents acknowledged several vulnerabilities due to the construction of flyover projects.

Among the respondents, a businessman expressed deep concern about the environment pollution caused by this flyover projects. To him, "Those people who are coming from Shonir Akhra, Jatrabari are being benefited from this flyover, but local businessman and inhabitants are facing different problems. You can see, the unhealthy environment and water logging caused severe health impact on the people living near the flyover. Even, sometimes it became difficult for patients to reach at the hospital timely. There are many deaths caused by this flyover which is unpublished by the newspapers." (Syful, Businessman, Age 37, Mayor Hanif Flyover, Dhaka). Another respondent who had been living near the Khilgaon flyover project also said, "People did not come here for house rent. There is always noise and sound pollution that make people not to decide to live here. Moreover, children are facing problems of going to school and very often they did not get interest of going to school." Besides, another respondents informed us, "This flyover decreased our trading. Previously, every day I used to sell 100 sack of cement, but now I can't make it 50. Customers did not want to come here as this area is highly over polluted. Poor drainage systems and the negligence of city corporations are mainly responsible for this toxic odor. I have to wear mask to do business as this odor is very much harmful for our physical and mental health." (Shopon, Age 30, Neighborhood Residence from Mayor Hanif Flyover)

Besides, we have found that these flyover projects have flourished the informal economy. And, this has created employment opportunities for the migratory people in the city. People from various peripheral regions are residing in the city for better work and better prospects and these generating tensions, violence and crises for the local businessmen near the flyover projects. Under the flyover, we have noticed that spaces are being occupied by different informal workers like tea sellers, vendors, hawkers etc.

Moreover, under this flyover we have also noticed that people are taking drugs which has created serious health hazards. One of the respondents from the Khilgaon fly over gave comment on this issue. He said, "People are taking drugs in front of the policeman. They take bribery from those who used to take drug. Moreover, we did not find any assistance from our word commissioner. He nev- 
er visited here for the last three years." (Shopon, Age 30, Neighborhood Residence from Mayor Hanif Flyover)

Now the questions come to us, why are we constructing flyover projects though these are creating several vulnerabilities on human life? To understand the reason behind this we need to go through over the development and underdevelopment theories. According to the modernization theories, third world countries like Bangladesh have traditional features such as poor infrastructure, low skilled labor, less developed technology. So, we need to develop our infrastructure if we really want to make progress. This conveys the utilization of various flyover projects with the collaboration of Public Private Partnership (PPP). But do all these infrastructural development really ensure sustainable development? To understand this, we need to go through over the dependency theories. According to the dependency theories, Third world countries are underdevelopment not due to its traditional infrastructure but due to its dependent relationship to the core capitalist countries [11]. As a result, these flyover projects mainly served the interests of the capitalist class under neoliberal scheme. While constructing flyovers various raw-materials, technology, expertise, design etc. are exported from the developed core countries like the USA, China, Russia as well as Britain. In this aspect, the role of State and its bureaucracy is to bring control and domination over the marginalized class so that they can't make any protest. Alavi and Amin in their study exclaimed that the state plays an ideological role for the capitalist class through continuous intervention [12]. Thus flyover projects in Dhaka City do little for the development of economy rather it creates several vulnerabilities by excluding local inhabitants from their normal activities. In the context of Mayor Hanif Flyover and Khilgaon flyover we also noticed that development and underdevelopment are intertwined together.

\section{Conclusion}

All over the world there is a growing consensus against constructing flyovers. Even Bangladesh data of STP (Strategic Transport Plan) does not support flyovers and subway in Dhaka [16]. The National Land transport policy which was adopted in 2004 does not support flyover and subway [8]. However, the government of Bangladesh initiated these megaprojects for reducing traffic congestion and people's sufferings. But the real scenario is different. Khilgaon and Mayor Hanif flyover depicted how those projects decreased local businesses, caused loss of lands, displacement of population and loss of social cohesion, loss of employment, potential health hazards, and negative impacts on environment as well as traffic congestion increased.

\section{Recommendations}

This study finds that vulnerabilities arising due to the studied flyovers are the result of unplanned construction. Some recommendations have come out from the discussions with the respondents. Some of them are following: 
1) It is essential to conduct social impact assessment and environmental impact assessment before the construction of flyovers.

2) Khilgaon, Chankharpul, Gulisthan, Jatrabari are mainly commercial areas. A lot of economic activities are operating here. If government takes better planning, it may reduce the loss of businessmen as well as the nearby neighborhoods.

3) When a new project will be taken, the government should give priority for ensuring compensation for the affected people.

4) Businessmen also claimed that they cannot handle goods easily because of narrow footpath. Proper planning could solve this problem.

5) A large amount of toll collection is another factor that motivates people not to use the flyovers. Responsible authorities should look at this point.

6) Making road divider tirelessly and at a good height results hindrance on movement. People of one side of the road cannot go to the opposite side. Respondents propose underpasses at several places as a solution to their problems.

\section{Acknowledgements}

We would like to express our gratitude to the Department of Sociology, University of Dhaka, for allowing us to do this study that has contributed greatly to enrich research potentialities. The completion of a research within a very short period of time accompanied by other course works was really a challenging task. However, we owe to our profound gratitude to our research supervisor, Professor Dr. Sadeka Halim, Department of Sociology, University of Dhaka. Without her perseverance and sincere supervision we could never arrive at this point of achievement. Lastly, we would like to thank all of the respondents who helped us to conduct this research.

\section{Conflicts of Interest}

The authors declare no conflicts of interest regarding the publication of this paper.

\section{References}

[1] The World Economic Forum (2018) The Global Competitiveness Report 2017-2018. http://www3.weforum.org/docs/GCR2017-2018/05FullReport/TheGlobalCompetiti venessReport2017\%E2\%80\%932018.pdf

[2] Kabir, S. (2014) Rethinking Overpasses: A Case Study in the Planning and Design of Flyovers in Dhaka City. Unpublished Master's Thesis, Harvard University, Graduate School of Design, Cambridge, 1-65.

[3] Demographia World Urban Areas (15th Annual Edition: 201904). http://www.demographia.com/db-worldua.pdf

[4] The Ministry of Finance (2013). https://mof.gov.bd/site/page/f9aab5cd-f644-47bb-bb94-a70cb64c15ce/Budget-in-Bri ef-(2000-01-to-2016-17) 
[5] Taleb, M. and Majumder, S. (2012) Impact of Flyovers in Dhaka City of Bangladesh on the Affected People in the Adjacent Area. International Journal of Engineering \& Technology, 4, 103-106. https://doi.org/10.7763/IJET.2012.V4.327

[6] Dhaka Transport Co-Ordination Authority (DTCA) (2010) Dhaka Urban Transport Development Study (DHUTS). Final Report, Bangladesh University of Engineering and Technology (BUET) and Japan International Cooperation Agency (JICA) Study Team.

[7] Bosunia, M. and Shamim, Z. (2019) How to Overcome Infrastructure Deficit in Bangladesh. The Daily Star.

https://www.thedailystar.net/star-infrastructure/news/how-overcome-the-infrastruc ture-deficit-bangladesh-1693408?browserpush=true

[8] Akther, S. (2009) A Big No to Flyover and Subway in Dhaka. The Daily Star. http://archive.thedailystar.net/newDesign/news-details.php?nid=113928

[9] Roushan, N. (2013) In the Shadow: A Study for Utilization of Space under Flyovers in Dhaka. Unpublished Bachelor Thesis, Department of Architecture, BRAC University, Dhaka.

[10] Peet, R. and Hartwick, E. (1999) Theories of Development. The Guilford Press, New York/London, 65-85.

[11] Webster, A. $(1984,1990)$ Introduction to the Sociology of Development. Palgrave, New York, 41-62. https://doi.org/10.1007/978-1-349-17667-0_3

[12] Alavi, H. (1972) The State in Post-Colonial Societies: Pakistan and Bangladesh. New Left Review, 74, 59-81.

[13] Dahrendorf, R. (1959) Class and Class Conflict in Industrial Society. Stanford University Press, Stanford.

[14] Coser, L. (1956) The Functions of Social Conflict. The Free Press, New York.

[15] Jia, G., et al. (2011) A Study of Mega Project from a Perspective of Social Conflict Theory. International Journal of Project Management, 29, 817-827. https://doi.org/10.1016/j.ijproman.2011.04.004

[16] (2005) Strategic Transport Plans for Dhaka. Louis Berger Group, Inc. and Bangladesh Consultants Ltd., Dhaka. 